\title{
Eidetic Variation: a Self-Correcting and Integrative Account
}

\author{
Jaakko Belt ${ }^{1}$
}

Received: 17 June 2021 / Accepted: 24 November 2021 / Published online: 27 December 2021

(c) The Author(s) 2021

\begin{abstract}
Edmund Husserl's eidetic phenomenology seeks a priori knowledge of essences and eidetic laws pertaining to conscious experience and its objects. Husserl believes that such eidetic knowledge has a higher epistemic status than the inherently fallible empirical knowledge, but a closer reading of his work shows that even eidetic claims are subject to error and open to modification. In this article, I develop a self-correcting account of Husserl's method of eidetic variation, arguing that eidetic variation plays a critical role in both challenging and improving upon the eidetic results in phenomenology. More specifically, I argue that the self-correcting account of eidetic variation 1) is consistent with Husserl's own formulations of his eidetic methodology and epistemic principles; 2) captures the dual epistemic function of eidetic variation as means for both testing and intuitively validating eidetic claims; and 3) offers methodological support for contemporary attempts to integrate eidetic variation with non-eidetic methods and resources. To substantiate these claims, I first contrast the self-correcting account with the falsificationist interpretations of eidetic variation. Then, I turn to three applications of eidetic variation in order to examine how eidetic phenomenology could draw from real-life deviations, artificial variations, and critical-historical reflection. The goal is to lay the methodological groundwork for a self-correcting and integrative account of eidetic variation and illustrate its usefulness in research practice.
\end{abstract}

Keywords Clarification · Edmund Husserl · Eidetic knowledge · Eidetic variation · Fallibilism · Falsification · Integrating methods · Intuition · Justification ·

Phenomenological methodology

Jaakko Belt

Jaakko.belt@tuni.fi; jaakko.belt@gmail.com

1 The History, Philosophy and Literary Studies Unit, Faculty of Social Sciences (SOC), Tampere University, Kalevantie 4, 33014 Tampere University Tampere, Finland 


\section{Introduction}

In Ideen I and III, Husserl introduces phenomenology as an eidetic science by opposing it to empirical or factual sciences. In Husserl's view, eidetic phenomenology differs from empirical sciences both methodologically and in the kind of knowledge it seeks. In short, eidetic phenomenology strives for a priori eidetic knowledge (Wesenserkenntnis), i.e., knowledge of essences and eidetic laws. By contrast, empirical sciences yield a posteriori factual knowledge (Tatsachenerkenntnis) of actually existing particulars, empirical generalities, and their contingent regularities. ${ }^{1}$ In order to change the perspective from particular facts and empirical generalities to pure essences and essential structures, Husserl proposes a methodological reorientation called "eidetic reduction". In the ensuing eidetic attitude the individual cases or particulars under study are treated as pure possibilities, i.e. conceivable instances of the investigated kind of phenomena. This entails excluding the question of their factual existence. (Hua III/1, 6-7, 20; Hua V, 40, 142; Hua IX, 284-285, 321-322; EU, §89) Eidetic inquiry, then, sets out to determine what is universally and necessarily valid for all conceivable (i.e. imaginable) cases of certain kinds of phenomena, that is, what belongs to their pure essence or eidos (Hua V, 40, 42, 47; cf. Hua III/1, §2, §3, §7, §34). Husserl believes eidetic phenomenology opens up an "endless field" of such eidetic truths, which can be brought to immediate insight and described systematically in eidetic investigations (Hua V, 43-45).

To cement the apparent dichotomy between empirical-factual and eidetic sciences, Husserl further emphasizes the methodological differences in their respective ways of acquiring knowledge. Whereas empirical sciences rely on observation and inductive generalization, eidetic phenomenology utilizes imagination and resorts to what Husserl in Ideen I calls ideation or "seeing" essences. In short, ideation is a complex cognitive act in which consciousness of something particular is transformed into an intuitive grasp of its essence. (Hua III/1, §§3-4, §7, §23; cf. Hua IX, 76) Husserl continued to refine and rearticulate the methodic form of ideational process in terms of eidetic variation (see Lohmar 2019). Simply put, eidetic variation is a procedure that starts with an exemplary instance of the investigated phenomenon and varies its features freely in imagination in order to retain an intuitive grasp of what stays invariant throughout the series of variations. Husserl believes the method of ideation (and eidetic variation as its refined form) allows the eidetic researcher to intuitively discern pure essences, whose essential features and connections can then be grasped conceptually, further analyzed and stated in eidetic judgments as eidetic laws (Wesensgesetze) (Hua XXIV, 226, 230-233, 326; cf. Hua III/1, §5, $\S 34, \S \S 65-66, \S 75, \S 135)$. Given the wide scope of eidetic investigations in Husserl's transcendental phenomenology, ideation is instrumental in establishing eidetic knowledge of the essential structures of consciousness and different kinds of lived

\footnotetext{
1 See Hua III/1, 6, 8, §2, §4, §7, §18; Hua V, 42. Cf. Hua XXIV, 230-231; EU, §86. Throughout the article, I use the abbreviation Hua (followed by the volume number) to refer to the Husserliana volumes and EU to refer to Erfahrung und Urteil (1939); references to the English translations of Husserl's work are provided only when they are quoted.
} 
experience, as well as eidetic laws concerning reality and different kinds of objectivities constituted in conscious experience (Hua III/1, §75, §135; Hua XXIV, 326, 333).

According to Husserl, the empirical and eidetic methods differ not only in how knowledge is acquired but also in how it can be challenged and validated or verified. The stark contrast between the two modes of knowledge is captured in a passage in Ideen III:

"Eidetic truths are absolutely binding, intransgressible [unüberschreitbare], not to be confirmed or refuted by any experience [Erfahrung]. Empirical truths [Erfahrungswahrheiten] [...] are accidental truths, which are modified and annulled through experience just as they are established through experience. They are only presumptively valid, subject to further experiential confirmation." (Hua V, 47-48; Husserl 1980, 41, translation modified)

Husserl maintains that even the strongest empirical truths based on experience (Erfahrung), including the laws of nature, are revisable. Empirical claims can always be challenged and revoked by further experience, because experience (ranging from simple sensory experience and everyday perception to experiential observation) yields only incomplete, imperfect or inadequate evidence, whose epistemic value can be increased and decreased. (Hua III/1, §19, §138; Hua XXIV, §51a,d) Therefore, empirical knowledge has only relative validity and justification as something probable (Hua XXIV, 343, 347). By contrast, Husserl believes ideation can, at least in certain domains, afford perfect, complete or adequate evidence, which cannot be gradually strengthened or weakened by further evidence (Hua III/1, §138, $\S \S 3-4) .^{2}$ In this ideal case, the object of knowledge is given in fulfilling intuition "as it is by itself, once and for all" (Hua XXIV, 341). According to Husserl, not only pure essences, but also their essential connections and eidetic laws can be given adequately, making their denial "absurd" (Hua XXIV, 231, 235, 336-337, 341). Hence, ideation enables acquiring a priori knowledge of eidetic laws, "whose validity in pure intuition is absolutely certain and indubitable" (Hua XXIV, 234-235).

The long-standing debate concerning the nature and function of eidetic variation challenges such a clear-cut distinction between eidetic knowledge and empirical knowledge. Many commentators argue for a fallibilistic reading of eidetic variation, according to which eidetic variation does not secure infallible knowledge but rather yields corrigible results. Such readings can be divided into three groups according to the main lines of argument they offer to motivate fallibilism. The discussion has long revolved around 1) inductionist arguments and 2) arguments from preknowledge. What I propose to call 3) falsificationist arguments, however, pose the most direct challenge to reconsider how eidetic knowledge can be established in phenomenology as an eidetic science.

The inductionist line of argument holds that eidetic variation and induction are more closely related than Husserl acknowledged. Already in 1947, Merleau-Ponty

\footnotetext{
2 Already in Ideen, Husserl acknowledged that ideation does not always, let alone in every domain, guarantee adequate evidence (see Hua III/1, 13-15, 344-345; Hua V, 86).
} 
(1964, 70-72) proclaimed that essential and inductive modes of knowledge are fundamentally homogenous: both are based on particular facts, even if induction uses effective variations of actually realized cases and eidetic variation relies on imaginative variation of example cases. The knowledge of essences is, therefore, experiential and essences are ultimately as contingent as facts. Less sweepingly, David Levin has argued that eidetic variation builds on the associative typifications and inductively grounded empirical types already operative in our experience of the world. In his reading, eidetic variation utilizes types as resources and tries to rearticulate them in a more refined and controlled way. Because of their common origin in facticity and typifying experience, pure essences differ from empirical-inductive types only in degree, and eidetic variation should be viewed as continuous with and complementary to inductive processes. ${ }^{3}$ Moreover, Levin argues that eidetic variation, like inductive generalization, effectively operates with a limited series of variations and is hence necessarily incomplete. Even if it could in principle go on indefinitely, it must be terminated before the full range of experience has been covered. Levin thus questions whether eidetic variation could ever provide the kind of complete or adequate evidence, which leaves no room for perfection. (Levin 1968, 1970, 176-177, 189-192).

The inductionist arguments based on similarities between eidetic variation and the inductive method can be challenged by accentuating their methodological differences (Kasmier 2010; cf. Sect. 4.2). The more basic claim that eidetic variation relies on prior (everyday or scientific) typification can be refined without adopting such a problematic analogy. The arguments from preknowledge maintain that eidetic variation presupposes some knowledge of the essences it seeks to study, no matter how prereflective, implicit, or vague it may be. Schütz (1959) already asked whether the process of ideation qua eidetic variation can free itself of our habitualized ways of knowing and what we deem typical in the natural attitude. The objection has since been restated as a direct charge of circularity, but the gist stays the same: eidetic variation demands preacquaintance with the subject matter in order to operate. $^{4}$ If the argument stands, the implication is that eidetic variation can never completely purify or liberate itself from its factual and historical origins, as Husserl had arguably hoped (see Hua IX, §8; EU, §§89-90). Neither can eidetic knowledge be fully separated from our everyday and empirical knowledge. This has pushed many commentators to reconceive the function of eidetic variation: its role is not discovering essences but clarifying what we are already familiar with, i.e., making our implicit knowledge of essences explicit. In other words, eidetic variation is needed to labor through our initially vague and often confused conceptions in order to reach a clearer and more intuitive grasp of essences. (Mohanty 1989, 33; Scanlon 1997; Lohmar 2019, 115, 121) In line with such arguments from preknowledge, I later

\footnotetext{
3 Levin 1970, 151, 187-189; cf. Levin 1968. Levin leans heavily on Schütz's (1959) influential reading of Husserl's doctrine of types and the constitution of empirical-typical generalities (see EU, §§82-83).

4 See Mohanty 1989, 32-33; Mohanty 1991. Scanlon (1997) reformulates the objection as a modern day version of Meno's argument:'[I]f the method is meant to achieve knowledge of eide, how can anyone be asked, in advance, to select an instance of an eidos and then to imagine a series of arbitrarily varied instances of the same eidos?"
} 
show that eidetic variation qua intuitive clarification has a positive epistemic role in refining eidetic claims and perfecting intuitive evidence, even though the ideals of adequate evidence and infallible knowledge were unattainable in practice.

Finally, the falsificationist arguments emphasize the usefulness of eidetic variation in critically assessing and testing our presumptive eidetic claims. Such approach has been defended by Richard M. Zaner and more recently Rochus Sowa. Zaner (1973b) has argued that the open-ended nature of eidetic variation and tentativeness of its results enable continual criticism, which he deems a defining feature of all epistemic claims. Sowa (2007) even claims that it is the falsifiability of eidetic claims what makes eidetic phenomenology scientific, rendering eidetic variation as a method of (in)validation through the attempt at falsification.

In what follows, I propose a self-correcting account of eidetic variation that combines the virtues of the aforementioned arguments from preknowledge and the falsificationist readings introduced above. More specifically, I argue that eidetic variation has a dual epistemic function in both challenging and improving upon eidetic knowledge in phenomenology. The article proceeds by assessing the strengths and weaknesses of Sowa's falsificationism (Sect. 2) and Zaner's idea of continual criticism (Sect. 3). Sowa and Zaner rightly emphasize that eidetic knowledge is always open to criticism and correction, but they end up overplaying the negative function of eidetic variation in falsifying or rejecting eidetic claims. Drawing from Husserl's own formulations of his eidetic methodology and epistemic principles, I argue that eidetic variation has an equally important positive role in clarifying essences and perfecting intuitive evidence for the sake of refining and validating eidetic claims. In this way, I explicate the epistemic function of eidetic variation qua intuitive clarification in order to further develop the arguments from preknowledge.

Having outlined the self-correcting account of eidetic variation, I evaluate its feasibility in research practice by turning to three contemporary applications that seek to integrate non-eidetic methods and resources with eidetic variation (Sect. 4). I conclude that conceiving eidetic variation as a self-correcting method that is open for integration is not only consistent with Husserl's writings, but it also benefits phenomenology in its critical pursuit of eidetic knowledge. More generally, it paves the way for understanding eidetic phenomenology as a historically progressing science that can accommodate and draw from the resources of other disciplines.

\section{Eidetic Variation}

In Phänomenologische Psychologie, Husserl articulates eidetic variation as moments, steps or levels of ideation (Hua IX, 76; cf. EU, 416). For the systematic purposes of this article, eidetic variation can be unpacked as a three-step procedure (see Hua IX, §9a,c,e,f; EU, §87a,e):

Step 1 Starting from an example, i.e. choosing an actual or imagined instance of a certain type of experience (or experienced object). 
Step 2 Freely varying the guiding example, i.e. producing an"infinitely open" multiplicity of variants in imagination.

Step 3 Intuitive grasping of what stays the same in running through variations, i.e. retaining the invariant.

To elaborate, the first step turns any individual case of the investigated phenomenon into a variant, which then serves as a "model" guiding the following variation. Its features should then be modified freely in imagination in the second step. Once the free variation has been carried out long enough to intuitively distinguish what coincides or overlaps throughout the series, the invariant features can be singled out in the third step. Husserl gives the retained invariant various names: eidos, pure essence, and universal or necessary form. He believes that what is registered intuitively or "seen" in eidetic variation as pure essences can, finally, be "grasped conceptually and expressed in the form of general eidetic laws" (Hua XXV, 245; cf. Hua III/1, 311-312). ${ }^{5}$

In the current debate, Sowa has challenged Husserl's "official account" of eidetic variation both in terms of its commitment to seeing essences and its ultimate function. He considers "essence" (Wesen) as a historically laden term, but for him "seeing essences" (Wesensschau) has been a particularly detrimental choice of words for the reception of Husserl's eidetic doctrine (Sowa 2007, 78). Due to Husserl's inadequate description of the method, Sowa argues, the practice of eidetic variation has been misunderstood as "intuitively singling out a chimerical entity in common" (Sowa 2010, 549). Sowa's alternative reading of eidetic variation offers a straightforward way of assessing presumptive eidetic claims intersubjectively and integrating varied resources into the eidetic process, but his account is curtailed by its commitment to a restricting form of fallibilism as falsification and by its failure to provide a positive account of validation.

\subsection{Sowa's Challenge: Eidetic Variation as Falsification}

Sowa points out that especially the later Husserl preferred universal statements in formulating descriptive eidetic laws such as:

"All imaginable acts have the moments, 'quality' and 'matter."'

"Every imaginable science departs from a life-world."

Sowa's key insight is that one can see from the logical form of these statements how they can be tested: since they claim unrestricted universal validity, finding a singular possible (i.e. imaginable) case that would falsify it is enough to challenge the eidetic law. In this way, the form of universal statements predelineates a procedure

\footnotetext{
5 Some commentators distinguish eidetic variation as a purely intuitive process of grasping essences from eidetic variation as the full-fledged method of discovering, formulating and validating eidetic laws (De Santis 2021; Majolino 2016). I deem it necessary to take both intuitive and predicative aspects of eidetic variation into account in assessing its functions in establishing eidetic knowledge. For Husserl, "all knowing is effected in judging, in predicating", while the resulting judgments and predications are, in turn, validated in fulfilling intuition (Hua XXIV, 214). More on this below.
} 
for testing and (in)validating eidetic claims. Sowa's falsificationist account of eidetic variation can also be construed as a three-step procedure. The process starts from a valid singular case of the presumptive eidetic law (step 1). Then, by varying its features the researcher attempts to find or construe potential cases that could invalidate the claim (step 2). If she succeeds in finding a counterexample in running through the potential falsifying cases or falsificants, the presumed law is falsified; if it passes the test, it is validated for the time being (step 3). Sowa calls the critical assessment of eidetic laws expressed in universal statements by searching for counterexamples "eidetic critique" (Sowa 2007, 100-102, 104; Sowa 2010, 549-551). ${ }^{6}$

Sowa's suggestion has two main strengths. First, his idea of "double testability" of eidetic claims outlines one possible and admittedly quite straightforward way of integrating both actual findings and imaginary cases into the eidetic procedure. Since actual and imagined experiences alike can be modalized into examples of pure possible experience that can equally serve as potential falsificants, candidates for falsification can be drawn from a wide variety of different sources. In Sowa's $(2007,106)$ words, these reservoirs include "the open-endless realm of imaginabilities" as well as "the spheres of scientific and pre-scientific experience". As I argue below, one can find support for integrative elements in eidetic variation both in Husserl's own presentation of his eidetic methodology (see Sect. 2.2) and contemporary research practice (see Sect. 4).

Second, Sowa's interpretation delineates one potential line of assessing the validity of eidetic claims intersubjectively. Since eidetic laws are confirmed only for the time being, "eidetic critique" is necessarily an open-ended process and eidetic claims can always be subjected to further testing. This counters the worry that phenomenological investigations tend to lead to stalemates and unresolved conflicts, since both sides can appeal to indubitable or incorrigible evidence (or counterevidence) (see Belt 2020; cf. Sowa 2007, 101, n51). Even in the face of indecision or disagreement, we can always search for counterexamples that would exclude one of the claims in order to adjudicate between competing descriptions. ${ }^{7}$ Sowa's proposal also undermines the allegation that eidetic methodology appeals to private and/or incommensurable evidence. Eidetic variation has an inherently public dimension not only because it can integrate empirical findings based on public observation into the eidetic procedure as potential counterexamples. What is considered possible and thus sufficient for challenging the eidetic claim under scrutiny must also be shown intersubjectively (Sowa 2010, 550; Mohanty 1991, 271). Consequently, it is up to the research community to debate if something is truly imaginable and whether a particular case or set of empirical findings presents counterevidence for a certain eidetic-phenomenological claim. As Sowa $(2010,551)$ rightly insists, the

\footnotetext{
${ }^{6}$ In Sowa's analysis, descriptive eidetic laws have the logical form: "It is true for every imaginable $\mathrm{x}$ that: if $x$ is (an) F, then $x$ is (a) G". In other words, eidetic laws are instantiated by particulars (x) falling under the essences $(F, G)$ in question. It follows that a singular case of the form " $x$ is (an) $F$, but not (a) G" counts as a falsifying counterexample.

7 Levin (1970, 107-108) noted that Husserl was unable to provide "a method for adjudication" determining which one of the putatively apodictic but conflicting insights is legitimate.
} 
intersubjective reassessibility of eidetic claims is essential to Husserl's conception of phenomenology as an eidetic science (see Hua III/1, §66, §87).

The weaknesses in Sowa's interpretation concern his narrow and one-sidedly negative understanding of the functions of eidetic variation. His revisionist reading of Husserl downplays the intuitive basis of eidetic knowledge, while it overemphasizes the role of falsification in producing phenomenologically relevant results. Crucially, the falsificationist account of eidetic variation falls short of accounting for direct validation of phenomenological claims. Instead of adhering to Husserl's own methodological and epistemic principles, Sowa ends up adopting a Popperian style doctrine of indirect validation through an attempt at falsification.

Husserl states repeatedly in Ideen I that phenomenology strives to be a descriptive science of pure essences within the limits of immediate intuition (Hua III/1, $127,138,139,156)$. For Husserl, the ultimate justifying and legitimizing source of knowledge is originary giving intuition in its different forms, as stated in the famous “principle of principles” (Hua III/1, §24; cf. §19, §141). Empirical sciences can rely on conducting experiments and making observations, since perception is a form of originary giving intuition and a source of justification in studying matters of fact (Hua III/1, §1, §7). Phenomenology must turn to the method of ideation, since for Husserl "seeing essences" (Wesenerschauung) is originary giving intuition and the ultimate justifying act of all eidetic sciences (Hua III/1, §§3-4, §7, §23). Hence, both empirical and eidetic knowledge draw their ultimate justification from intuition or "seeing" in the wide sense of becoming conscious of the investigated object itself directly "in person" (leibhaftig):

"Immediate 'seeing', not merely sensory, experiential seeing, but seeing in general as originary giving consciousness of whatever kind, is the ultimate source of legitimacy [Rechstquelle] of all rational claims. [...] If we see an object with full clarity, if we have explicated and conceptualized it on the basis of purely seeing and what is grasped within the limits of actually seeing [...], then the assertion which expresses the object faithfully has its legitimacy [hat ihr Recht]." (Hua III/1, 43; cf. §3, §24, §136)

It follows that eidetic claims draw their validity either from direct "seeing" (direkt "sehen") or from its derived form, mediated insight (mittelbar "einsehen"), since "all mediated grounding [Begründung] leads to immediate [grounding]" (Hua III/1, 314, 326, 328, cf. 21, 42). To my knowledge, Sowa neither explicitly challenges Husserl's epistemic principles nor attempts to reconcile them with the idea of (in)validation through falsification.

Husserl's later formulations of his epistemic principles diminish the role of intuition and put more weight on critically examining current evidence. In stating his "first methodological principle" in Cartesianische Meditationen, Husserl emphasizes the need for reflecting upon the range and perfection of the evidence in question before claiming any final validity (Hua I, 54). Similarly, in discussing "the most general principle of justification" in Erste Philosophie, Husserl calls for testing (erproben) all evidence and verifying (bewähren) our judgments and beliefs (Hua VIII, 32-33). In other words, we have to subject our cognitive operations and their results to further critical reflection to convince ourselves that the evidence they 
purportedly yield is really justified. This is especially true if one claims to have obtained adequate evidence understood as ideal perfection; only reflective evidence can tell us whether full intuitive clarity and completeness required by adequacy is still lacking. (Hua VIII, 31, 33) In seeking apodictic evidence in the sense of absolute certainty, reflective probing involves an attempt to doubt or negate the evidence at hand (Hua VIII, 35). Absolute justification would require nullifying all conceivable doubts about what is judged and convincing oneself of the impossibility of its non-being, but testing may as well lead to restricting the scope of the purportedly adequate or apodictic evidence (Hua VIII, 31, 36). ${ }^{8}$ Reflectively probing judgments that claim adequacy or apodicticity comes close to Sowa's idea of "eidetic critique".

Indeed, I believe that any viable reading of eidetic variation should embrace its critical potential to test our purported eidetic claims. For Husserl, eidetic variation plays a role not only in coming to know or "winning" pure essences and eidetic laws intuitively, but also in testing whether what seems or feels necessary actually is an apodictic necessity (Hua IX, 70-72, 322-323). Still, Husserl holds on to the phenomenological notion of direct givenness in reformulating his epistemic principles. According to the most general principle of justification, knowledge can be accepted as finally valid only in cases, where what is posited in our judgments is grasped and seen exactly as it is meant - as "itself stand[ing] before our eyes" (Hua VIII, 32, 36). Even if Husserl shuns the word "intuition", he still views self-givenness (Selbstgebung or Selbstgegebenheit) as the ultimate measure of justification (Hua VIII, 32-33). Furthermore, he believes that verifying our judgments involves self-grasping (Selbsterfassung) the investigated object or state of affairs (Hua VIII, 34). Falsificationist accounts of eidetic variation should either be made consistent with Husserl's epistemic principles or be supplemented with an alternative positive account of validating eidetic claims.

Sowa's falsificationism diverges from Husserl's commitment to direct intuitive givenness or self-givenness in arriving at and validating phenomenological results. Here, Sowa bypasses textual evidence underlining the specific role Husserl gives to eidetic variation in evoking eidetic insights and providing the intuitive basis for eidetic claims in his later writings. ${ }^{9}$ He also presents falsification of the descriptive eidetic laws as "the method of validation required by their general form" (Sowa 2007, 78). In citing the logical form of eidetic claims as universal statements and then inferring that a single counterexample (i.e. a case ruled out by the presumptive law) suffices to refute them, he effectively adopts the hypothetical-deductive model of reasoning favored by Popper among others. However, indirect inferences like deduction, analogies and other "non-intuitive procedures [Verfahrungsweisen]" have methodological relevance for Husserl's phenomenology only insofar as they subsequently allow for direct intuitive discernment of essential features and connections (Hua III/1, 157-158). Falsification provides only indirect and mediated support for

\footnotetext{
8 As Cai (2013) has noted, Husserl even sometimes characterizes apodictic evidence as "probe-evidence" (Probe-evidenz). See Hua XXXV, 387, cf. 384-385.

${ }^{9}$ For example, in Erfahrung und Urteil Husserl characterizes free variation as the foundation (Grundlage) and basis (Grund) of essential seeing (Wesenserschauung) (EU §87a,d; cf. Hua IX, 84).
} 
eidetic claims in case the search for counterexamples falls short, not yet phenomenological results.

Sowa $(2007,102)$ does not hesitate to claim that searching for potentially invalidating counterexamples to the purported eidetic laws by imagining extreme and unfamiliar cases is the "true methodological place" of eidetic variation. In this regard, his conception of eidetic critique follows Popper's $(1968,51)$ idea of criticism as "an attempt to find the weak spots in a theory", especially in its logical consequences. Furthermore, Sowa $(2007,106)$ explicitly applies Popper's criterion of testability or falsifiability of theories to determine the scientificity of individual eidetic statements. However, Popper $(1968,51)$ himself insisted that theories (and by Sowa's extension, singular hypothesis or universal laws) can never be proven or justified but only refuted with counterexamples (cf. Sowa 2007, 106). If eidetic variation serves neither the discovery of eidetic laws nor intuition of essences, as Sowa (2007, 103) insists, and if eidetic statements can only be refuted but never directly validated, are eidetic claims no more than mere hypotheses in the Popperian sense? How does one come up with such presumptive universal statements? What are the phenomenological criteria for holding eidetic claims justified?

The inherent tension between the Husserlian and Popperian elements leads to inconsistencies in Sowa's account of validation. On the one hand, Sowa states that eidetic laws can be considered valid only for the time being, if the candidates for counterexamples have failed or examples taken as falsificants are in fact revealed impossible on closer inspection. Even if no counterexamples or even promising candidates are in view and the eidetic law can thus be considered well-proven, the possibility for future falsification cannot be eliminated. ${ }^{10}$ On the other hand, Sowa claims that in some cases the possibility of falsification can be ruled out (in fact, apodictically eliminated) by insightfully showing their immunity to falsification. At least some eidetic statements and laws in phenomenology satisfy, in his mind, this stronger claim of apodicticity. (Sowa 2007, 104) It remains unclear, however, how this distinction can be made without appealing to immediate intuition or degrees of intuitive evidence in establishing an insight into "immunity of falsification". Husserl himself was adamant in claiming that the apodictic results of eidetic variation are such that we can intuitively see the impossibility or inconceivability of their negation, their non-being (Hua XVII, 256; cf. Hua I, 56; Hua VIII, 35; Hua XXXV, 385 ). Challenging this prima facie Husserlian position requires a positive account of validation showing how "immunity of falsification" can be established. Otherwise insisting on falsifiability as the criterion of scientificity but granting irrefutability to some results of phenomenology as an eidetic science is to have your cake and eat it too.

\footnotetext{
10 As a case in point, Sowa (2007, 104, n58) refers to mathematical conjectures (e.g. the Goldbachian conjecture), which "are indeed proven through countless positive examples" but "for which a proof is still lacking at this point".
} 


\subsection{The Positive Functions of Eidetic Variation}

Apparently, Sowa's commitment to the Popperian negative understanding of falsification makes him hesitant to give a more positive epistemic role for eidetic variation. Following the Popperian ideal of testing as refuting, falsification via eidetic variation leads to restricting or simply abandoning the eidetic claim in question (Sowa 2007, 101-102, cf. 104). As the arguments from preknowledge indicate, however, eidetic variation can also serve the function of intuitive clarification. Developing this line of thinking further, I contend that intuitive clarification of essences via eidetic variation can increase the legitimacy of eidetic claims under scrutiny by enhancing the intuitive givenness of what is investigated. In fact, conceiving eidetic variation as a method for incremental improvement of evidence helps to reconcile the negative aspect of testing with the positive demands of Husserl's epistemic principles. This lays the epistemological basis for the selfcorrecting account of eidetic variation developed below.

In $\$ \$ 67-70$ of Ideen I, Husserl describes the eidetic procedure in terms of the interconnected methods of clarifying essences (Wesensklärung) and grasping essences (Wesenserfassung). Eidetic methodology aims to grasp essences in their complete or perfect clarity, but Husserl's emphasis on clarification demonstrates the stepwise and gradual nature of this process. If fleeting experiences present themselves as vaguely distant or intuitively empty to reflective investigation, as is often the case in Husserl's view, our determinations of the corresponding essences based on those examples remain unclear, vague, and indefinite as well. As Husserl puts it: "Grasping an essence has, therefore, its degrees of clarity, in the same way as does the individual floating before us." (Hua III/1, 141) To press the point, Husserl presents clarity as a gradual concept, ranging from complete lack of clarity, non-intuitiveness, and obscurity to "full clarity, intuitiveness, givenness" as its respective limits (Hua III/1, 142). He thinks that for each essence there is so-called "absolute proximity" (absolute Nähe), in which this ideal clarity and self-givenness has been reached. For eidetic method to attain the goal of perfect intuitive givenness of essences and essential connections, it is necessary to bring the corresponding moments in individual examples closer to perfect clarity accordingly. (Hua III/1, 141) Even in cases where the original example affords sufficient intuitive basis for attaining a fully clear apprehension of essential generality (Wesensallgemeinheit), Husserl stresses that

"there is a lack of clarity in determining more precisely the essences that are interwoven with it [mitverflochtenen Wesen]; hence, it is necessary to bring the individualities serving as examples into closer proximity [Näherbringen] or to procure others that are better suited, in which the individual features, first sought in confusion and obscurity, stand out from one another and can then come to be given in the clearest possible way." (Hua III/1, 144-145; Husserl 2014, 124)

Later on in Ideen III, Husserl writes along the same lines that the intended object "must be brought to ever greater clarity, must be brought ever nearer, must be brought in the process of clarification to perfect self-givenness" (Hua V, 
103; Husserl 1980, 89). Whether or not the ideal of perfect clarity or full intuitive givenness, i.e. adequate evidence, is attainable in practice, Husserl clearly embraces the possibility of incrementally improving upon intuitive evidence of essences.

Husserl also discusses the value of empirical, historical, and fictional sources in this context of clarifying and grasping essences. Their utility for eidetic phenomenology is neither in simply refuting (as counterexamples) nor confirming (as positive examples) presumed eidetic claims (see Hua III/1, §70; Hua V, 47-48, 51). Such resources rather help to procure clear intuitions by providing stable, vivid, detailed or otherwise useful exemplary instances of the investigated types of experience and objects. Whatever their origin, exemplary intuitions can serve as the starting point of ideation and eidetic analyses in general in an effort to attain a clearer and thus more adequate grasp of the corresponding essences. (Hua III/1, §70; §4; cf. Hua V, 51-53) If imagination by itself fails to provide clear intuitions, Husserl believes it can and should be furnished with exemplary intuitions from other sources (Hua V, 53; Hua III/1, 148). Furthermore, he calls for "pollinating" (Befruchtung) imagination with "the richest and best possible observations" before engaging in free phantasy (Hua III/1, 148). In this regard, everyday perceptions and observations in the experimental setting are valuable as originary giving intuitions, but Husserl advocates drawing from the teachings of history and even works of fiction as well. Obviously, one has neither (f)actual examples nor artistic creations at one's disposal to cover every possible experience, but "pollinating" gives imagination more intuitive material to work with to widen its range. Finally, Husserl notes how geometry utilizes models and drawings for not only inciting exemplary intuitions but also retaining the steps and results of the eidetic procedure executed in and by imagination. (Hua III/1, 147-148; Hua V, 52-53) Perceptual illustrations and instrumental means can be utilized analogously in eidetic phenomenology (Hua V, 52-53; Hua III/1, 148). Husserl's use of two-dimensional time-diagrams to illuminate the complex structure of time-consciousness is a fitting example (see Dodd 2005).

Hence, experiential "reservoirs" have a more positive and diverse role in supporting eidetic methodology than simply providing invalidating counterexamples for discarding eidetic claims. To restate these supportive functions in terms of eidetic variation, external resources and instrumental means can 1) offer intuitive starting examples for the variation process, 2) provide illuminating material for extending its scope, and 3) retain and illustrate its results for future variation. Supportive resources alone, though, would not be enough for attaining eidetic knowledge - not without the methodological contribution of operating in free phantasy. According to Husserl, it is necessary "to utilize imagination abundantly [reichlich] in the here required complete clarification, in the free reconfiguration of what is given in phantasy" (Hua III/1, 148). The point is not developed further in Ideen I, but in retrospect, Husserl comes close to professing the need for free imaginative variation in intuitive clarification and grasping of essences. Given the close connection between increasing intuitive fulfillment and the progress of knowledge examined already in Logische Untersuchungen (see Hua XIX/2, 539-540, 597-598, 614-615, 627), the clarificatory work opens up an important epistemic role for eidetic variation. 
Commentators who subscribe to the arguments from preknowledge often hold that eidetic variation provides clarification of meaning, sense or concepts (see e.g. Mohanty 1989, 33; Mohanty 1991; Lohmar 2019). Sowa (2007, 103, n56) also maintains that eidetic variation is useful in scrutinizing conceptual scopes, anchoring concepts and making vague everyday language more precise by varying the starting examples falling under certain concepts and especially in running through borderline cases. Nevertheless, for him conceptual clarification plays merely a provisional role, since the ultimate goal of eidetic phenomenology is the construction and verification (or rather falsification) of synthetic law-statements. In other words, concepts are intuitively "deepened" and "calibrated" only in relation to their place and function in formulating eidetic laws (Sowa 2010, 548). Husserl does indeed emphasize that scientific knowledge is expressed in correct statements and he extends the method of clarification to statements as "the element in which science lives" (Hua III/1, 289; cf. 10-11, 140). He further links the supposed validity of scientific statements to the validity of concepts with which sciences operate, predicate and relate to their domains of possible objects. Moreover, concepts might lack epistemic validity (Erkenntnisgeltung) because of their unclarity. (Hua V, 94-97).

For Husserl, however, clarification of concepts and their judicative use has its basis and source of validity in eidetic intuition. In Ideen III, he speaks of "eidetic definitions" of basic concepts "drawn purely out of intuition" (Hua V, 27-29; cf. Hua I, 54, 180). Husserl illustrates this by clarifying the concept of material thing through free variation of both imagined and actually perceived material bodies (Körper), arriving at the intuitive grasp of its essence as res extensa (Hua V, §7). ${ }^{11}$ In Cartesianische Meditationen, Husserl states that intuitive consciousness of something universal based on eidetic variation, i.e. eidos as it is "seen", is "prior to all concepts" and that pure concepts must conform to eide (Hua I, 105). In procedural terms, linguistic analyses of the meaning of complex concepts and equivocal words do have a propaedeutic function in making them semantically, logically or analytically distinct (Verdeutlichung), but Husserl insists that the main work of clarification (Klärung) in the phenomenological sense consists in making them intuitive (Hua V, 101-102; Hua I, 54; cf. Hua XLI, No. 3, 53-54). He gives a dual meaning for such a process of intuitive clarification. On the conceptual side, it means making concepts clear by recourse to intuitions fulfilling them. On the objective side, it means bringing the meant object, i.e. the essence corresponding to the concept, progressively closer to complete self-givenness as described above. (Hua V, 102-104) In both senses, intuitive clarification has a more fundamental role in Husserl's eidetic

\footnotetext{
11 Husserl's other recurrent example object of eidetic clarification is decahedron (Hua V, §20; Hua XLI, 52). Contrary to what the paradigmatic examples might suggest, the scope of eidetic variation is not restricted to intentional objects of experience (such as material thing, triangle, tone or color) and types and forms of intentional experience (e.g. perception). For Husserl, eidetic variation is equally instrumental in analyzing the subject of experience eidetically in its embodied relation to the world. The transition from my factual ego to eidos ego (or transcendental ego in general) is effected by what Husserl calls self-variation (Selbstvariation). This involves running through possible variations of myself (my lived body, my habitualities, my surrounding world etc.), i.e. imagining myself as being otherwise. (Hua I, 102, 105-106, 110, 117; De Santis 2020).
} 
phenomenology than Sowa gives it credit for. Insofar as clarification is aided by eidetic variation, the methodological function it serves exceeds the mere explication of concepts in view of constructing eidetic statements.

The epistemic potential of any fallibilistic reading of eidetic variation ultimately hinges on how the negative aspect of testing eidetic claims coheres with the positive prospect of attaining and improving intuitive evidence validating them. As I argued above, Husserl's reformulated epistemic principles promote critical self-reflection on the validity of judgments through weighing their supposed evidence. Husserl's elaborations on these principles also support the idea that there is room for incremental improvement of evidence even in instances claiming adequacy or apodicticity. In Erste Philosophie, Husserl entertains the possibility that perfect self-givenness might be a "mere idea", which could be approximated in a continuous series of increasing evidences but may never be attained (Hua VIII, 33-34). He further characterizes adequate evidence as the ideal limit or optimum of ascending levels of evidence, corresponding to a gradual scale of satisfaction of our striving for knowledge (Hua VIII, 34-35; cf. Hua XIX/2, 614-615). Where judgments still lack perfect selfgivenness, they can only be accepted as intermediary stages (Zwischenstadium) to final validity, to borrow a phrase from Cartesianische Meditationen (Hua I, 54).

Hence, Husserl's reformulated epistemic principles set normative ideals or guiding norms for seeking eidetic knowledge - epistemic goals that might be realized in phenomenological practice only partially and piecemeal. I take this interpretation to be in line with those commentators who maintain that Husserl's epistemic principles and ideals are consistent with fallibilism in general (see Berghofer 2018; Berghofer 2019; Heffernan 2009). More importantly, it paves the way for the particular fallibilistic reading of eidetic variation as a self-correcting method that I next turn to.

\section{A Self-Correcting Account of Eidetic Variation}

Husserl debated the issues of fallibility and eidetic intuition with his contemporary critics, most notably the Neo-Kantians and empirical psychologists of his time. A case in point is a manuscript titled "Zur Kritik an Theodor Elsenhans und August Messer" drafted by his assistant Edith Stein on Husserl's behalf in 1917 (Hua XXV, 226-248). The manuscript confronts the supposed infallibility and incorrigibility of the eidetic procedure head on:

"The independence of phenomenology from all experience [Erfahrung], an independence which precludes the possibility of a correction [Korrektur] of eidetic knowledge through psychological experience, has always caused a particular kind of offense. One has seen in this a claim to infallibility [Unfehlbarkeit], a claim to the impossibility of error. This, however, has never been claimed; nor is this in any way implied by our stress on the particular laws and the particular characteristics of eidetic knowledge. There is no scientific knowledge that is absolutely immune from error." (Hua XXV, 246; Husserl and Stein 2018, 466, translation modified) 
In other words, eidetic phenomenology must be open to correction like any other science. The manuscript cites "countless errors" in the history of mathematics and logic to highlight that even other eidetic sciences using eidetic intuition are subject to revision. In eidetic disciplines errors can occur for example if investigations are cut short prematurely or previous analyses and conceptual determinations are used vaguely or from memory without revisiting the original intuition. Even claims of necessity might prove to be in need of modification if further investigations show they have been accepted too hastily. But susceptibility to error does not call into question the prospect of obtaining firm results or undermine the idea of complete or fully intuitive evidence. (Hua XXV, 246-247) This is consistent with the interpretation of Husserl's reformulated epistemic principles as guiding norms or ideals presented in the previous section.

If this is true, how do empirical findings in particular challenge eidetic claims? Furthermore, how can the questioned eidetic claims reclaim justification? Consider the following example given in the manuscript:

"Suppose that I have concluded that the essence of thing-perception implies the seeing of things; and suppose now that I am presented with a person blind since birth, for whom the sense of touch is sufficient for the constitution of spatial things; in that case, I recognize that I have not pursued the free formation of possible modifications of perception far enough. But it is not the faktum of the blind person's perception that shows me this; it is the eidetic possibility of such perception, which I grasp in going over from experience to the eidetic attitude." (Hua XXV, 248; Husserl and Stein 2018, 467)

This hypothetical case highlights how an eidetic claim (visual perception is a necessary feature of thing-perception) can be challenged by an empirical counterexample (people blind since birth manage to constitute spatial things tactually). Importantly, the original claim is not directly invalidated or abandoned. Instead, previously unregarded findings make the phenomenologist attentive to shortcomings in her eidetic claim, prompting her to return to eidetic variation in search of further evidence. More specifically, the counterexample is turned into a variant (taken as a pure possibility rather than a factum) and incorporated into a new series of variation in imagination. The original claim can thus be reassessed and modified accordingly only on the basis of intuitive evidence evoked by such an enriched variation whose scope is extended by the findings (see Hua XXV, 247-248).

The picture of testing and modifying eidetic claims provided by the manuscript is far from the Popperian idea of falsification. The kind of fallibilism defended by Stein and Husserl proceeds by way of revisiting and refining rather than refuting eidetic claims. This self-correcting form of fallibilism also shows how testing claims is tightly connected to their justification in eidetic variation. In Sowa's account, eidetic variation provides only indirect support for eidetic claims, while the self-correcting reading defended here shows how taking findings into account and integrating them into eidetic variation can actually improve intuitive evidence and directly validate the modified eidetic claims.

The self-correcting account has some affinities with Zaner's classic fallibilistic interpretation of eidetic variation, which anticipated Sowa's position in many ways. Drawing 
from Formale und transzendentale Logik, Zaner (1972, 221-223) argues that for Husserl degrees of clarity and perfection and possibility of deception pertain to every kind of evidence and that "absolute evidence" is an ideal norm. Therefore, eidetic judgments claiming apodictic evidence are open to error, modification, and rejection (as well as confirmation) and must be subjected to continual criticism like every other epistemic claim (Zaner 1972, 224; Zaner 1973b, 37). Echoing the Stein-Husserl manuscript, Zaner $(1973 b, 37)$ mentions sources of error typical of eidetic knowledge, stemming from or connected to eidetic variation: the range of examples might be insufficient and the scope of variation too restricted or carelessly probed. There is always an element of arbitrariness in deciding if and when eidetic variation has been taken "far enough". The openness of variation enables revisiting or reiterating the process and renders the evidence in question processual (rather than acquired in a single vision). (Zaner 1973b, 33, 39-40) This is why Zaner deems certain tentativeness an essential feature of eidetic claims (Zaner 1973b, 37, 39-40; Zaner 1973a, 218). This is broadly in line with the account defended here.

But there are important differences as well. Considering Zaner's insistence on tentativeness and the processual and gradual nature of evidence, his views on (in)validation are strikingly rigid and categorical. Even though he explicitly avoids speaking of "falsification", a single instance to the contrary suffices to "reject" the supposed eidetic claim. In his mind counterexamples show that we were mistaken to believe that the eidetic claim was true in the first place, or rather, that it was an eidetic claim at all:"the very notion of a "false" eidetic claim is an essential absurdity". (Zaner 1972, 228-229; Zaner 1973b, 39) Conversely, no amount of confirmation or verification can increase (or diminish) the eidicity of eidetic claims (while confirmation usually increases the likelihood of empirical claims). In other words, continuous criticism can only determine the status of a presumptive claim categorically: "It either is or is not eidetic, one either correctly or incorrectly believes it to be eidetic" (Zaner 1972, 229).

What exactly, then, is the positive contribution of eidetic variation in epistemic criticism? Zaner (1973b, 36-37) holds that evidence both for and against eidetic claims is methodologically connected with reflectively assessing ever more exemplifications of the supposed invariancy through eidetic variation. But how does repeating variation validate or strengthen the eidetic claims withstanding critical assessment, that is, make them more evident or provide further evidence of their correctness? Conversely, is rejecting the supposed eidetic claim (or denying its "eidicity") really the only way forward in the face of counterevidence - should not revising it present an equally plausible and often preferable option? If indeed "truth is an idea, lying at infinity" (Hua XVII, 284; cf. Zaner 1972, 221), how does eidetic research approach it in practice? Ultimately, Zaner's call for continual criticism faces challenges similar to Sowa's eidetic critique in accounting for direct validation of eidetic claims. Answering the questions above requires a more detailed positive account of eidetic variation and its epistemic functions than either Sowa or Zaner provides. The self-correcting approach to eidetic variation as a method for clarification of essences and incremental improvement of intuitive evidence is the way forward. 


\section{An Integrative Account of Eidetic Variation: Three Cases}

In the current research, there are several potential applications of eidetic variation, which more or less explicitly embrace its fallibility. In explicating the prerequisites for a fruitful exchange between eidetic phenomenology and empirical investigations, Zahavi writes:

"For Husserl, we can obtain insights into essential a priori structures through eidetic variation. However, such insights always possess a certain provisionality, a certain presumptiveness, and necessarily remain open for future modifications in the light of new evidence. [...] Our a priori knowledge is, in short, fallible; if we come across putative empirical counterexamples to our alleged eidetic insights, they need to be taken seriously and cannot simply be dismissed as irrelevant. In fact, if we want to test and probe the validity of our eidetic claims, considering a range of more or less exceptional cases might be quite illuminating." (Zahavi 2017, 155; cf. 150, 153)

In short, Zahavi believes real-life deviations observed in fields like psychopathology, social and developmental psychology, and neurosciences can support imagination in scrutinizing our tentative claims of necessity and disclosing unnoticed features of conscious experience (see also Parnas and Zahavi 2000).

Froese and Gallagher (2010) propose another application or rather an extension of eidetic variation by artificial means. Drawing from research methods and practices in the field of study called artificial life (Alife), they suggest computer simulation can provide modern technological supplementation to eidetic variation by externalizing some of the work done by imagination. They effectively adopt a fallibilistic position in citing the limitations of human imaginative capacities and the difficulties in establishing the essential features of complex material and empirical phenomena, especially the phenomenon of life and biological embodiment, as reasons for utilizing technologically induced hypothetical variation in phenomenological research.

The third methodological development seeks to reconcile eidetic variation with Husserl's method of critical-historical reflection. Along the lines of the arguments from preknowledge, Aldea (2016) maintains that Husserl's eidetic phenomenology necessarily relies on historically embedded typifications and concepts. However, she argues that this background guiding our epistemic practices can be turned into a valuable resource for eidetic variation. If we succeed in drawing self-critically rather than blindly borrowing from the sources of our traditions, the argument goes, eidetic variation allows us to identify, circumscribe, and even overcome deeply entrenched epistemic boundaries with the help of imagination.

These contemporary applications share with the traditional fallibilistic readings of eidetic variation the conviction that it is impossible to fully separate the eidetic from the empirical and historical. Rather than treating this entanglement as an insoluble tension at the heart of Husserl's phenomenology or an insurmountable obstacle for eidetic variation, they seek to turn it to the advantage of eidetic phenomenology. They suggest ways in which eidetic variation can draw from different sources and be supplemented by other methods or research practices. The readiness to incorporate 
external resources into eidetic phenomenology and to integrate supportive methods with eidetic variation are the main features of what I refer to as an integrative approach to eidetic variation.

The previous sections have already disclosed integrative elements in Husserl's eidetic methodology. Section 2 laid the methodological grounds for utilizing experiential, historical, and fictional sources as well as instrumental means to the benefit of eidetic phenomenology, especially in support of eidetic variation. Section 3 outlined a way of integrating challenging material into the eidetic procedure through self-correcting eidetic variation. In this section, I illustrate the feasibility of an integrative self-correcting account of eidetic variation in practice by examining the potential of the three applications introduced above.

\subsection{Real-Life Deviations}

Analogous to the hypothetical case of blindness in the Stein-Husserl manuscript, Parnas and Zahavi (2000, 9-11) have suggested that eidetic phenomenology can and should draw from documented real-life deviations. They argue that actual deviations might play a role similar to thought experiments more reliably by providing a rich source of challenging and illuminating cases. In addition to testing universalistic assumptions and scrutinizing the limits of intuition, anomalous cases might, by way of contrast, prompt us to revise and refine our analyses and elucidate elusive or overlooked aspects of what is deemed normal experience (see also Zahavi 2017, 152-153).

In principle, real-life deviations can be captured by a variety of third-, secondand first-person methods. Potential methods range from neuroimaging techniques to experimental and observational methods in psychological research, interviews and case studies in clinical settings, and autobiographical accounts. ${ }^{12}$ In practice, as Zahavi (2017, 152-153) notes, the most natural and fruitful source of phenomenologically relevant accounts of experience are disciplines offering detailed personlevel descriptions. Historically speaking, phenomenologically oriented psychology and psychiatry have provided valuable accounts, especially on psychopathological phenomena, such as self-disorders discussed below (see Spiegelberg 1972; Fuchs 2013). Merleau-Ponty can be considered a precursor of the integrative approach, not only because of his engagement with developmental psychology, but also for utilizing case studies for the purpose of eidetic research. ${ }^{13}$ More recently, phenomenology has engaged in constructive dialogue with cognitive sciences. Findings and theoretical influences travel both ways, enabling what Zahavi calls "productive cross-fertilization" between transcendental-eidetic phenomenology and empirical disciplines broadly construed (see Zahavi 2017, 151-154).

However, one must be careful in how to extract phenomenologically relevant knowledge from empirical or clinical settings. Caution is equally needed in

\footnotetext{
12 For utilizing autobiographical accounts in phenomenological psychopathology, see Bortolan 2019.

13 A paradigmatic example is the famous Schneider case, see Jensen 2009.
} 
integrating the obtained insights into eidetic research. Even though Zahavi emphasizes testing our presumptive eidetic claims and accommodating potential empirical counterexamples, he does not promote falsification as the way of incorporating real-life deviations into eidetic phenomenology. He is particularly careful not to claim that third-person findings about sub-personal processes, mechanisms, neural correlates and the like would straightforwardly refute or confirm phenomenological accounts. They can only motivate or complement further phenomenological investigations that must be conducted in experiential terms. (Zahavi 2017, 152, 155-156)

Zahavi also points out problems with relying on external observation and second-personal interpretation when it comes to clinical cases involving atypical experience. For instance, there is an often-cited risk that medical personnel project their own preconceptions onto patients in trying to take the perspective of other by imagining how their experience differs from one's own. ${ }^{14}$ To mitigate such bias, the patient's own perspective has to be integrated into the investigation. But as Zahavi (2020) notes, this poses a further challenge for interviewing patients: how to elicit answers that reflect their experience faithfully and comprehensively? The methodological issues in conducting interviews in a phenomenologically fruitful way are not restricted to clinical cases, but rather concern second-person methods of gathering and analyzing descriptions of experience in general.

Even when clinical and empirical studies provide reliable and phenomenologically relevant person-level descriptions, utilizing them in eidetic research is by no means uncomplicated. Parnas and Zahavi $(2000,10)$ remind us that real-life deviations such as pathological phenomena are always subject to interpretation, like empirical findings more generally. The prevalence of anomalous cases, their theoretical impact and their significance in challenging our habitual typifications (and ultimately, the idea of an invariant core) are all issues demanding further consideration. The effects of real-life deviations on our eidetic claims are, hence, often hard to determine conclusively. Psychopathological descriptions of self-disorders are a case in point. Recently, the impact of schizophrenic thought insertion on the experiential notion of minimal selfhood in particular has raised controversy. In short, there is an ongoing debate on whether episodes of thought insertion constitute a counterexample to the claim that conscious experiences are universally and necessarily characterized by for-me-ness or minimal selfhood (or its aspect called sense of ownership) (see Henriksen et al. 2019; Zahavi 2020).

\footnotetext{
14 See Zahavi 2020. Clinical cases, such as the locked-in syndrome in Zahavi's analysis and self-disorders discussed below, raise broader methodological questions concerning eidetic variation: Does imagining and emphatically understanding how others (might) experience involve at least implicit self-variation, i.e. imagining myself as being otherwise? To what extent is conceiving others and possible experiences in general anchored in and limited by the embodied perspective of the researcher engaging in self-variation and eidetic variation? Husserl's treatment of such questions, particularly from the transcendental standpoint, and their methodological implications are gaining some attention in Husserl scholarship (see Lobo 2013; de Santis 2020). However, their ramifications for current research practice require further consideration. Acknowledging potential egocentric limitations in grasping bodily and worldly experiences different from one's own is crucial for self-critical application of eidetic variation, especially in investigating topics such as gender, race, and (dis)abilities.
} 
Commenting on the thought insertion debate, Henriksen et al. (2019) point out several methodological issues with using psychopathological descriptions for philosophical purposes. Sometimes patients' subjective reports are taken at face value or interpreted literally. Careful analyses provided by earlier psychopathological research are ignored as well. Selective use of examples, often recycled in the literature, can also lead to both ignoring and overemphasizing certain experiential aspects of thought insertion. The effect is only amplified if the motivation is to provide invalidating counterexamples of certain theories of selfhood or consciousness, rather than representing the phenomenon itself comprehensively. Finally, Henriksen, Parnas, and Zahavi argue that thought insertion should be investigated embedded in and often arising from the altered experiential framework of schizophrenia spectrum disorders, not as isolated and decontextualized experiences. They back their claim with phenomenologically informed empirical studies: schizophrenia spectrum disorders are not only associated with certain anomalous self-experiences but also frequently accompanied by specific disturbances in the patient's embodied experience of the world and others (cf. Parnas and Henriksen 2019). Henriksen et al. (2019) conclude that thought insertion involves a disturbance of for-me-ness resulting from increased self-alienation (manifested in various anomalous self- and world-experiences), rather than a complete lack of minimal self or a dissipation of first-person perspective.

Bearing these methodological restrictions in mind, how can real-life deviations be integrated into the eidetic procedure through eidetic variation? How does their inclusion benefit eidetic phenomenology? It seems clear that real-life deviations can support eidetic variation in all three ways laid out in Sect. 2.2. Using exceptional cases (instead of typical or familiar ones) as a guiding model for variation admittedly runs the aforementioned risk of overemphasizing certain features. But in their ability to highlight what is usually taken for granted and to capture quite strikingly what is missing, anomalous experiences can also provide an intuitive starting example for grasping otherwise unnoticed features and separating truly essential features from what is merely typical. Furthermore, as carefully detailed cases they are well suited for concrete exemplifications and vivid illustrations of earlier eidetic results. Most importantly, real-life deviations often reveal our ignorance about the range of experiences of certain kind. Some anomalous cases can even change the whole notion of what is conceivable for a category of experiences. By showing that the scope of factual variation is actually wider than previously thought or deemed possible, real-life deviations also serve the third supportive function of "pollinating" imagination.

Anomalous cases can be integrated into the eidetic procedure even more directly along the lines suggested by the Stein-Husserl manuscript. To recap, deviances can make us aware of potential insufficiencies in our eidetic descriptions, push us to reiterate eidetic variation and, finally, incorporate the exceptional experiences to the variation process. The improvement upon the evidence provided by such an enriched eidetic variation can be further articulated as intuitive clarification of the investigated phenomenon. In Ideen I, Husserl distinguishes between two interlinked 
processes of "normal clarification" or making something clear to oneself. On the one hand, one can illustrate or make something intuitive. On the other hand, one can enhance the clarity of something already intuitive. ${ }^{15}$ To further instill this distinction, Husserl separates extending the scope of clarity from increasing the intensity of clarity (Hua III/1, §68). He admits that we often have only "impure" intuitions at our disposal, but they are crucial as intermediate stages or "stepping stones" in perfecting evidence (Hua III/1, 144).

Anomalous cases seem particularly suitable for procuring such imperfect intuitions, since they highlight specific features of the investigated phenomenon vividly, even if other aspects would remain unclear. But as the thought insertion debate shows, real-life deviances can also shed light on the wider experiential context of the phenomenon under study. This enables intuitive differentiation of the previously indeterminate or even obscure essences interwoven with the investigated essence, to borrow Husserl's expression quoted above (Hua III/1, 144-145). For instance, phenomenologically enlightened analyses of the schizophrenia spectrum disorders indicate that disturbances in one aspect of experience (e.g. minimal self) are often entangled with more or less pervasive changes in other basic structures of experience (e.g. intentionality, embodiment, temporality, and intersubjectivity) (see e.g. Fuchs 2013; Ferri and Gallese 2019; Parnas and Henriksen 2019). This can guide further investigations into such interconnected aspects of experience and lead to more refined analyses of their essential connections.

To restate Parnas' and Zahavi's suggestion in Husserlian terms: First, concrete empirical findings and person-level descriptions pointing to real-life deviations can bring complex, uncharted and even previously inconceivable features of experience to the scope of intuition by extending the range of eidetic variation. Second, they can increase or enhance the intuitive clarity of phenomenological claims by forcing us to return to eidetic variation, in order to reconsider their correctness and modify eidetic descriptions according to the newfound evidence. Hence, including anomalous cases to eidetic variation can play a significant role in revising and refining eidetic claims. Phenomenology can, thus, accommodate and learn from anomalous experiences without espousing a falsificationist reading of eidetic variation or abandoning its eidetic ambitions.

\subsection{Artificial Variation}

Alife research utilizes simulation models to study complex phenomena such as the self-constitution of living organisms, adaptive behaviour, and the emergence of embodied cognition (Froese and Gallagher 2010, 93-94). Froese and Gallagher (2010, 97, 100-101) assert that creating hypothetic variation by running simulations

\footnotetext{
15 The dense passage reads in German as follows: "Das Sich-klar-machen besteht also hier in zweierlei miteinander sich verbindenden Prozessen: in Prozessen der Veranschaulichung und in solchen der Steigerung der Klarheit des schon Anschaulichen. [...] Damit ist aber das Wesen der normalen Klärung beschrieben." (Hua III/1, 144)
} 
can serve the same function as eidetic variation in scrutinizing the essential features of (possible) biological phenomena or "life-as-it-could-be". In their view, simulation models amount to "opaque thought experiments", since they use hypothetical cases for probing what is conceivable in order to reveal unexpected or non-intuitive consequences. This could both challenge claims of necessity or unfounded presuppositions and extend the scope of imagination, redirecting empirical and phenomenological research alike.

The initiative is admittedly bold and has some enticing potential. Simulations could be seen as a digital extension of the supportive functions Husserl gives to the "artificial arrangements" of experimental psychology and using models and drawings in mathematical thinking (Hua V, 52-53). Froese and Gallagher (2010, 90, $92-93,97,102)$ indeed commend the pedagogical value of working with simulations and the stability of computer medium for repeated test runs. For them, however, simulations serve a more ambitious goal than procuring exemplary intuitions before eidetic variation or retaining its results after the actual work done in imagination. They argue that simulation models can produce otherwise unattainable insights by surpassing both empirical variability and what can be performed by unaided human imagination. In their mind, real-world phenomena like living bodies with nervous systems in changing environments are too complex, unpredictable, and holistic to get a grasp on by means of imaginative variation or experimental protocols and empirical observation alone.

One can find some support for the last claim in Husserl's writings. In Phänomenologische Psychologie, he acknowledges that some essences and their correlative concepts (like "color" and "tone") are quite easily intuitively grasped with ideation, while other essences such as lived body (Leib), animate being, and human being in general might present themselves non-intuitively in vague or empty concepts. In the latter case, essences can only be established progressively by producing manifold of intuitions to realize such empty meanings - it might even take "an entire infinite science" to unfold their eidetic features. (Hua IX, 90, 92-93) Husserl would thus agree with the quite plausible assumption that there are more and less complex essences and levels of difficulty in grasping them in practice. Rather than proving that some essences are categorically too complicated to grasp, however, I would argue that complex and multifaceted essences profess the need for eidetic variation to bring their empty, confused or equivocal meanings gradually to their intuitive fulfillment through conceptual and intuitive clarification of their often entangled essential features, along the lines presented in the previous sections.

Froese and Gallagher do not fully elaborate on where the difficulties with relying on human imagination lie. However, their line of argumentation points to a general worry in Husserl's eidetic methodology. If eidetic variation must run through multiplicity of modifications and keep the successive earlier configurations in mind to grasp the invariant (see EU, §87c), the task may soon prove to be insurmountable. Our capacity to envisage possible experiences and modify them could in practice be decisively hindered if the reflected phenomenon is too complex or detailed. The sheer number of options might simply overwhelm our imagination, and the procedure could run its course before the needed variation for clear intuition of essences is formed. An optimistic reading of Froese and Gallagher's proposal is that computer 
simulations manage to exceed our imagination by relieving its cognitive burden: externalizing imaginative variation to a more stable computer medium and controllable environment arguably allows for more effective and systematic variations and their iteration (see Froese and Gallagher 2010, 97, 102).

This interpretation is problematic. It follows the inductionist line of argument in assuming that eidetic variation suffers from incompleteness due to our practically limited capacity to produce variants or cover the full range of possibilities (Kasmier 2010). Husserl clearly states, however, that there is obviously no need to actually run through every option available to grasp essential features of the object under investigation. Rather than requiring an exhaustive process producing final results, imagination aims at an "infinitely open" multiplicity of variants. For imaginative variation to be free, it needs to stay open and arbitrary in the sense of acknowledging that it could go on at will and at any time draw from whatever source at hand. This arbitrariness or optionality (Beliebigkeit) differentiates eidetic variation from empirical induction (or empirical variation, in Husserl's terms), which generalizes by running through a certain (finite) number of actual instances. (Hua IX, 76-77; Hua XVII, 255) Computer simulations might support imagination in keeping the realm of possibilities open, but eidetic variation does not require computational efficacy to cover the wealth of options in order to succeed.

Furthermore, the real difference between imaginative variation and computer simulation lies in the intuitiveness and non-intuitiveness of their respective procedures Froese and Gallagher (2010, 97, 101-102) admit that the biggest drawback of variation by simulation is that its results lack intuitive (self-)evidence, acknowledging that their meaning always requires further analysis and interpretation. If variation is not produced or performed by a conscious subject, how can there be an intuitive grasp of essential features?

To their credit, Froese and Gallagher readily concur that this is the very opacity characterizing the procedure. In promoting the analogy and even certain methodological continuity between imaginative variation and computer simulations, however, they seem to underestimate the scope of difficulties faced in the non-intuitive way of proceeding. Husserl was cautious of mediated ways of proceeding in eidetic phenomenology because retaining an intuitive grasp of not only the starting point and the end result but also every step of the procedure was regarded as integral to seeing what stays invariant in different configurations (Hua IX, 78). This is why he defended operating in phantasy and using continuous series in eidetic variation. When it comes to Alife simulations, neither the process nor the outcome is self-evident. After all, Alife tries to design simulation models in which the designer intervenes in its operation as little as possible, in order to reveal the implications of our explicit premises or ingrained assumptions and to examine unforeseen consequences of theoretical positions (Froese and Gallagher 2010, 95, 97, 102).

From the phenomenological perspective, interpreting the insights produced by simulation in experiential terms poses the biggest challenge for integrating Alife methodology with eidetic variation. Following Husserl, Froese and Gallagher (2010, 92-93) note that imagined, lived through, and encountered instances are in principle on the same level as potential variants, as long as they are considered as pure possibilities. This paves the way for simulation as a potential mode of variation. To 
be included in eidetic variation, however, pure possibilities have to be transformed or shaped into variants, i.e. intuitively imagined by the researcher as one optional example among other conceivabilities (Erdenklichkeiten) (Hua IX, 71, 76-77, 86; EU, 411; Hua I, 66, 104-105). In eidetic variation, each variant alongside the process itself appears, as Husserl puts it, "in the subjective mode of lived experience of the "optional"" (Hua IX, 73). These requirements put pressure on Alife research to convey its insights in a re-conceivable way, i.e. as possibilities actually and intuitively imaginable in the subjective mode of presentation, not only as theoretical or conceptual possibilities intended merely symbolically or "emptily" in thought (see Jansen 2020). For instance, running simulations with adaptive artificial agents in virtual environments or evolutionary robots in laboratory settings produces behavior whose meaning as possible embodied and embedded experience is far from clear. ${ }^{16}$ Alife might make it easier to envision simple forms of life-as-it-could-be and help to scrutinize the essential features of living being(s) eidetically, but by itself it says little about the experiential or conscious aspects of lived being (Froese and Gallagher 2010, 84; Froese et al. 2012). Yet phenomenologists are primarily interested in the lived body and the first-personal aspect of biological embodiment.

A more recent call for a human-centered synthetic approach, which draws from Alife and enactive robotics to design systems for actual human participants instead of artificial agents, seems more promising. Froese et al. (2012) have proposed "artificial embodiment" as a method for studying "mind-as-it-could-be" from the first-person perspective. The basic idea is to vary or alter person's embodiment, and thereby their experience, by technological means, especially human-computer interfaces. Research done and tools developed in fields like haptics, virtual reality systems, and prosthetic technology could be utilized in "engineering for experience". The goal is to technologically enlarge the domain of experiential phenomena by giving rise to novel experiences and even modifying the structures of lived experience, in order to analyze their essential features and conditions of possibility. Froese et al. consider their method more empirically grounded than imaginative variation, since variations in (user) experience are brought about by controlled, systematic, and verifiable technological changes. However, as long as the emerging experiences are described in sufficient detail with suitable first- and second-person methods, they could well be incorporated into and further analyzed with eidetic variation too. Technological modulation or mediation can alter our experience by way of augmentation, substitution, and deprivation (Froese et al. 2012). Artificial embodiment could thus serve functions similar to real-life deviations in providing eidetic variation with cases of anomalous and unfamiliar bodily experience, fuelling the study of "mind-as-itcould-be" unsevered from the lived body.

Notwithstanding the methodological restrictions in obtaining factual variation from human subjects in the experimental setting, drawing from artificially generated

\footnotetext{
16 The problem of meaning concerns not only the attribution of an intrinsically meaningful perspective for the artificial agent (see Froese and Ziemke 2009), but also the more practical difficulties in interpreting the results experientially as an external observer running the simulations (let alone as someone reading about them) (cf. Ziemke and Taguchi 2019).
} 
but still actually lived through experiences documented in experiential terms has clear advantages over purely hypothetical variation via computer simulation. It seems easier to integrate eidetic variation with artificial embodiment than Alife, when embodied human subjects are a more integral part of the "artificial variation" process from the outset.

\subsection{Critical-Historical Reflection}

If eidetic variation is as dependent on habitual typifications, historically sedimented concepts, and concealed cultural senses as the arguments from preknowledge suggest (see Lohmar 2019, 112, cf. 130), there is certainly a pressing need to engage self-critically with the historically embedded resources eidetic variation unavoidably draws from. In this regard, Aldea's hermeneutically oriented proposal to supplement eidetic variation with teleological-historical reflection, as Husserl conceives it especially in the Krisis manuscripts, is particularly promising. Overcoming the apparent tension between eidetic variation as an apriori transcendental-eidetic method and Husserl's reflective historical analyses, sometimes voiced as challenges of ahistoricism and Eurocentrism, further motivates this type of integration (see Aldea 2016; Aldea 2017).

Whereas the Husserl of Ideen I deemed "the renditions of history" useful mainly in enriching imagination before the eidetic procedure (Hua III/1, 148), later Husserl eschewed the idea of philosophers simply drawing from history as something external to them. ${ }^{17} \mathrm{He}$ rather professed the need for a critical-historical reflection (Besinnung) of our "historical past" and clarification of our ultimate goal or telos in order to understand ourselves as philosophers carrying on a living tradition with its "spiritual inheritance" and often concealed history (Hua VI, 15-16, 510-513). Following Husserl's turn to "our history", Aldea (2016) argues that uncovering and probing what already guides us and currently holds us captive as phenomenologists doing research in a certain historical situation is crucial for the epistemic success of the variation process itself. Aldea notes that historically sedimented types and concepts not only bind the constitution of the guiding example as an instance of a certain kind, but also stimulate and sustain the subsequent series of variations. We should, therefore, survey their limits (or "modal boundaries") and potential (or "modal potency") in generating conceivable possibilities. Furthermore, scrutinizing other historically determined factors steering our imagination is decisive for imaginative variation to succeed in surpassing the limits of conceivability initially suggested by earlier classifications and generalization.

\footnotetext{
${ }_{17}$ In 1935 , Husserl writes that history is not at philosophers' disposal like "stocks piled up in a storehouse" (Hua VI, 511; cf. 16).
} 
A more detailed exposition of Aldea's theoretical account lies outside the scope of this article. Assessing the full value of critical-historical reflection for eidetic variation in research practice would also require varied example cases. Suffice to say, Husserl's late manuscripts lend support to the idea that supplementing eidetic variation with teleological-historical reflection serves, besides its self-critical role, the positive epistemic function of clarification introduced above. ${ }^{18}$ This widens the potential uses of history in eidetic methodology from merely an illustrative source or a reserve of falsifying counterexamples to a more integral part of self-correcting eidetic procedure. It also opens the way for conceiving eidetic phenomenology as a historically progressing science, perhaps even as a "rigorous science" whose idea - sometimes expressed explicitly as the idea of attaining absolute knowledge (Hua III/1, 8) - is "realized only in an unending historical process" (Hua V, 139).

\section{Conclusion}

In this article, I have defended a self-correcting account of eidetic variation. How does it square with Husserl's early statement, quoted in Introduction, that experience neither refutes nor confirms the "intransgressible" eidetic truths? One option would be to argue that Husserl simply changed his views. After all, in Formale und transzendentale Logik, he famously states that every kind of evidence can turn out to be "deception", annulled by new evidence that future experience provides (Hua XVII, 164). Taken at face value, this would suggest eidetic knowledge is not only fallible but also refutable by empirical evidence. Husserl hastens to add, though, that it takes similar evidence to "shatter" what was ostensibly apodictic evidence (Hua XVII, 164). In other words, empirical observation as such does not suffice to (in)validate eidetic claims, since the source of eidetic evidence is not perception but ideation. As the Stein-Husserl manuscript states, experience (Erfahrung) by itself does not correct eidetic knowledge, although empirical evidence can reveal potential errors and prompt the phenomenologist to test the eidetic results. Only eidetic intuition affords the required eidetic insights for correcting them. ${ }^{19}$ The more nuanced fallibilistic reading developed along these lines holds that eidetic claims can be revised and perfected, but only by returning to the eidetic attitude and re-engaging in eidetic variation. This is the self-correcting aspect of the account defended in this article.

This reading clearly contrasts with the conviction that eidetic phenomenology secures perfect and indubitable results, valid once and for all. Still, as argued above,

\footnotetext{
18 In The Origin of Geometry, Husserl links "epistemological elucidation" and clarification with reflective historical inquiry, stating: "Every explication and every transition from making explicit [Verdeutlichung] to making self-evident [Evidentmachung] [...] is nothing other than historical disclosure" (Hua VI, 379; Husserl 1970, 370). The method for obtaining invariants or essences in the horizon of historical life-world and making them evident (even apodictically evident) is eidetic variation (Hua VI, 383).

19 „Die Erfahrung kann den Wesensforscher darauf aufmerksam machen, daß in seinen Feststellungen ein Fehler stecken muß, sie kann ihn veranlassen, diese Feststellungen in einer neuen Intuition zu prüfen und zu berichtigen, aber sie selbst kann nicht als Berichtigung dienen: Denn nur in Wesensanschauung kann ich Wesenseinsichten gewinnen." Hua XXV, 248, cf. 246.
} 
it converges with Husserl's own principles conceived as norms or ideals guiding epistemic striving, in particular the quest for adequate and apodictic evidence. The self-correcting account of eidetic variation reflects the practical difficulties in seeking eidetic knowledge about lived experience and its objects with limited human imagination and open-ended methodology. Concurrently, it shows how piecemeal advancements in eidetic-phenomenological research are possible. Husserl came to recognize that conceiving evidence as absolutely indubitable insight would render attaining truth miraculous and prevent us from understanding the production of scientific results (Hua XVII, §§59-60). This article has taken the opposite route by examining the production of eidetic knowledge in terms of corrigible eidetic claims grounded on gradually perfectible intuitive evidence. This enables a reconciliation of the negative and positive functions of eidetic variation as a self-correcting method for testing and validating eidetic claims.

Moreover, conceiving eidetic phenomenology as a progressive science that claims no absolute immunity from error makes it easier to integrate it with other disciplines, including empirical sciences. The integrative account of eidetic variation embraces the prospect of drawing from non-eidetic resources and supporting it with supplementary methods. In the previous sections, I have laid out the supportive functions of utilizing external resources before and after eidetic variation and evaluated potential ways of enhancing and extending the variation process itself. The contemporary integrative applications examined above illustrate how non-eidetic disciplines could provide eidetic variation intuitive material to work with in clarifying and refining eidetic descriptions, not only counterexamples for challenging eidetic claims. In this way, the applications suggest possible ways of overcoming some of the limitations of eidetic variation. Yet they also reveal methodological restrictions in utilizing non-intuitive second- or third-personal methods and source material conveyed in non-experiential terms.

The list of potential resources for eidetic variation examined in this article is by no means exhaustive. In fact, openness for further extensions is a built-in feature of the integrative account defended here. Incorporating underutilized material into the eidetic procedure and supplementing eidetic variation with previously ignored methods is, after all, always possible and even desirable. Further integration might not only provide support in attaining the epistemic goals of eidetic phenomenology, but also unlock overlooked functions of eidetic variation. Once the methodological groundwork for an integrative and self-correcting account of eidetic variation has been laid, the benefits of utilizing different kinds of resources in eidetic phenomenology should be evaluated case-by-case and measured in research practice.

Acknowledgements This article was developed in presentations given at the annual NoSP conference in Copenhagen 2019, at the "Phenomenological Perspectives on Empathy and the Significance of Empirical Research. Women in Phenomenology: Edith Stein" conference in Graz 2019 and at the FiPhi 2020 Colloquium in Helsinki. Earlier versions of the manuscript were also presented at the Phenomenology Seminar in Helsinki and at the Doctoral Seminar in Tampere. I wish to thank everyone who attended these events for their helpful feedback. I am particularly grateful to Mirja Hartimo, Leila Haaparanta, Sara Heinämaa, Smaranda Aldea, and Ilpo Hirvonen for invaluable discussions and insightful comments on the manuscript. I would also like to thank the anonymous reviewers for useful comments and suggestions. 
Funding This work was supported by the Finnish Cultural Foundation (Suomen Kulttuurirahasto) and City of Tampere's research foundation (Tampereen kaupungin tiederahasto).

\section{Declarations}

Conflicts of interest The authors declared that they have no conflict of interest.

Open Access This article is licensed under a Creative Commons Attribution 4.0 International License, which permits use, sharing, adaptation, distribution and reproduction in any medium or format, as long as you give appropriate credit to the original author(s) and the source, provide a link to the Creative Commons licence, and indicate if changes were made. The images or other third party material in this article are included in the article's Creative Commons licence, unless indicated otherwise in a credit line to the material. If material is not included in the article's Creative Commons licence and your intended use is not permitted by statutory regulation or exceeds the permitted use, you will need to obtain permission directly from the copyright holder. To view a copy of this licence, visit http://creativecommons.org/licen ses/by/4.0/.

\section{References}

Aldea AS (2016) Phenomenology as critique: teleological-historical reflection and Husserl's transcendental eidetics. Husserl Stud 32:21-46

Aldea AS (2017) Making sense of Husserl's notion of teleology: normativity, reason, progress and phenomenology as 'critique from within.' Hegel Bull 38(1):104-128

Belt J (2020) Phenomenological skepticism reconsidered: a Husserlian answer to Dennett's challenge. Front in Psychol 11:2058. https://doi.org/10.3389/fpsyg.2020.02058

Berghofer P (2018) Why Husserl is a moderate foundationalist. Husserl Stud 34(1):1-23

Berghofer P (2019) On the nature and systematic role of evidence: Husserl as a proponent of mentalist evidentialism? Eur J Philos 27(1):98-117

Bortolan A (2019) Phenomenological psychopathology and autobiography. In: Stanghellini G et al (eds) The Oxford handbook of phenomenological psychopathology. Oxford University Press, Oxford, pp 1053-1065

Cai W (2013) From adequacy to apodicticity: development of the notion of reflection in Husserl's phenomenology. Husserl Stud 29:13-17

De Santis D (2020) "Self-variation": a problem of method in Husserl's phenomenology. Husserl Stud 36:255-269

De Santis D (2021) Eidetic method. In: De Santis D, Hopkins BC, Majolino C (eds) The Routledge handbook of phenomenology and phenomenological philosophy. Routledge, London New York, pp 175-186

Dodd J (2005) Reading Husserl's time-diagrams from 1917/18. Husserl Stud 21:111-137

Ferri F, Gallese V (2019) The bodily self in schizophrenia: from phenomenology to neuroscience. In: Stanghellini $\mathrm{G}$ et al (eds) The Oxford handbook of phenomenological psychopathology. Oxford University Press, Oxford, pp 1109-1123

Froese T, Gallagher S (2010) Phenomenology and artificial life: toward a technological supplementation of phenomenological methodology. Husserl Stud 26:83-106

Froese T, Ziemke T (2009) Enactive artificial intelligence: investigating the systemic organization of life and mind. Artif Intell 173(3-4):466-500. https://doi.org/10.1016/j.artint.2008.12.001

Froese T, Suzuki K, Ogai Y, Ikegami T (2012) Using human-computer interfaces to investigate 'mind-asit-could-be' from the first-person perspective. Cognit Comput 4:365-382. https://doi.org/10.1007/ s12559-012-9153-4

Fuchs T (2013) The self in schizophrenia: Jaspers, Schneider, and beyond. In: Stanghellini G, Fuchs T (eds) One century of Karl Jaspers' General Psychopathology. Oxford University Press, Oxford, pp 245-257

Heffernan G (2009) On Husserl's remark that “"[s]elbst eine sich als apodiktisch ausgebende Evidenz kann sich als Täuschung enthüllen..."' (XVII 164:32-33): does the phenomenological method yield any epistemic infallibility? Husserl Stud 25:15-43 
Henriksen MG, Parnas J, Zahavi D (2019) Thought insertion and disturbed for-me-ness (minimal selfhood) in schizophrenia. Cons Cogn. https://doi.org/10.1016/j.concog.2019.102770

Hua I. Husserl E (1973) Cartesianische Meditationen und Pariser Vorträge, Strasser S (ed). Martinus Nijhoff, Den Haag

Hua III/1. Husserl E (1976) Ideen zu einer reinen Phänomenologie und phänomenologischen Philosophie. Erstes Buch: Allgemeine Einführung in die reine Phänomenologie, Schuhmann K (ed). Martinus Nijhoff, Den Haag

Hua V. Husserl E (1952) Ideen zu einer reinen Phänomenologie und phänomenologischen Philosophie. Drittes Buch: Die Phänomenologie und die Fundamente der Wissenschaften, Biemel M (ed). Martinus Nijhoff, Den Haag

Hua VI. Husserl E (1954) Die Krisis der europäischen Wissenschaften und die transzendentale Phänomenologie, Biemel W (ed). Martinus Nijhoff, Den Haag

Hua VIII. Husserl E (1996) Erste Philosophie (1923/24). Zweiter Teil, Boehm R (ed). Kluwer, Dordrecht

Hua IX. Husserl E (1962) Phänomenologische Psychologie. Vorlesungen Sommersemester 1925, Biemel W (ed). Martinus Nijhoff, Den Haag

Hua XVII. Husserl E (1972) Formale und transzendentale Logik. Versuch einer Kritik der logischen Vernunft, Janssen P (ed). Martinus Nijhoff, Den Haag

Hua XIX/2. Husserl E (1984) Logische Untersuchungen. Zweiter Band. Zweiter Teil. Elemente einer phänomenologischen Aufklärung der Erkenntnis, Panzer U (ed). Martinus Nijhoff, Den Haag

Hua XXIV. Husserl E (1984) Einleitung in die Logik und Erkenntnistheorie. Vorlesungen 1906/07, Melle U (ed). Martinus Nijhoff, Den Haag

Hua XXV. Husserl E (1986) Aufsätze und Vorträge (1911-1921), Nenon T, Sepp HR (eds). Martinus Nijhoff, Den Haag

Hua XXXV. Husserl E (2002) Einleitung in die Philosophie. Vorlesungen 1922/23, Goossens B (ed). Springer, Dordrecht

Hua XLI. Husserl E (2012) Zur Lehre vom Wesen und zur Methode der Eidetischen Variation, Fonfara D (ed). Springer, Dordrecht

EU. Husserl E (1939) Erfahrung und Urteil. Untersuchungen zur Genealogie der Logik, Landgrebe L (ed).Academia, Prague

Husserl E (1970) The crisis of European sciences and transcendental phenomenology, trans Carr D. Northwestern University Press, Evanston

Husserl E (1980) Ideas pertaining to a pure phenomenology and to a phenomenological philosophy: third book, trans Klein TE, Pohl WE. Martinus Nijhoff, Den Haag

Husserl E (2014) Ideas for a pure phenomenology and phenomenological philosophy: first book, trans Dahlström DO. Hackett, Indianapolis

Husserl E, Stein E (2018) Critique of Theodor Elsenhans and August Messer (1917) (Edith Stein's draft), trans Clarke E. In: Staiti A, Clarke E (eds) The sources of Husserl's 'Ideas I.' De Gruyter, Berlin, pp $449-468$

Jansen J (2020) Imagination in the midst of life: reconsidering the relation between ideal and real possibilities. Husserl Stud 36:287-302

Jensen RT (2009) Motor intentionality and the case of Schneider. Phenomenol Cogn Sci 8(3):371-388

Kasmier D (2010) A defense of Husserl's method of free variation. In: Vandevelde P, Luft S (eds) Epistemology, archaeology, ethics: current investigations of Husserl's corpus. Continuum, London, pp 21-40

Levin DM (1968) Induction and Husserl's theory of eidetic variation. Philos Phenomenol Res 29(1):1-15

Levin DM (1970) Reason and evidence in Husserl's phenomenology. Northwestern University Press, Evanston

Lobo C (2013) Self-Variation and self-modification or the different ways of being other. In Jensen RT, Moran D (eds) The phenomenology of embodied subjectivity. Contributions to phenomenology, vol. 71. Springer, Cham, pp 263-283

Lohmar D (2019) The phenomenological method of eidetic intuition and its clarification as eidetic variation, trans Kee H. In: Drummond JJ, Höffe O (eds) Husserl. German perspectives. Fordham University Press, New York, pp 110-138

Majolino C (2016) "Until the end of the world": eidetic variation and absolute being of consciousness-reconsideration. Res Phenom 46:157-183

Merleau-Ponty M (1964) Phenomenology and the sciences of man, translated by Wild J. In: Edie JM (ed) The primacy of perception. Northwestern University Press, Evanston, pp 43-95

Mohanty JN (1989) Transcendental phenomenology. An analytic account. Basil Blackwell, Cambridge (Mass.) 
Mohanty, JN (1991) Method of imaginative variation in phenomenology. In: Horowitz T, Massey GJ (eds) Thought experiments in philosophy. Rowman and Littlefield, Savage, pp 261-272

Parnas J, Zahavi D (2000) The link: philosophy-psychopathology-phenomenology. In: Zahavi D (ed) Exploring the self: philosophical and psychopathological perspectives on self-experience. John Benjamins, Amsterdam, pp 1-16

Parnas J, Henriksen MG (2019) Selfhood and its disorders. In: Stanghellini G et al (eds) The Oxford handbook of phenomenological psychopathology. Oxford University Press, Oxford, pp 465-474

Popper K (1968) Conjectures and refutations, 2nd edn. Harper \& Row, New York

Scanlon J (1997) Eidetic method. In: Embree L et al (eds) Encyclopedia of phenomenology. Kluwer, Dordrecht, pp 168-171

Schütz A (1959) Type and eidos in Husserl's late philosophy. Philos Phenomenol Res 20(2):147-165

Sowa R (2007) Essences and eidetic laws in Edmund Husserl's descriptive eidetics. New Yearb Phenomenol Phenomenol Philos 7:77-108

Sowa R (2010) The universal as "what is in common": comments on the Proton-Pseudos in Husserl's doctrine of the intuition of essence. In: Ierna C, Jacobs H, Mattens F (eds) Philosophy, phenomenology, sciences. Essays in commemoration of Edmund Husserl. Springer, Dordrecht, pp 525-558

Spiegelberg H (1972) Phenomenology in psychology and psychiatry. Northwestern University Press, Evanston

Zahavi D (2017) Husserl's legacy. Oxford University Press, Oxford

Zahavi D (2020) Locked-in syndrome: a challenge to standard accounts of selfhood and personhood? Neuroethics 13(2):221-228

Zaner RM (1972) Reflections on evidence and criticism in the theory of consciousness. In: Embree LE (ed) Life-world and consciousness: essays for Aron Gurwitsch. Northwestern University Press, Evanston, pp 209-230

Zaner RM (1973a) The art of free phantasy in rigorous phenomenological science. In: Cairns D, Kersten F, Zaner RM (eds) Phenomenology: continuation and criticism. Martinus Nijhoff, Den Haag, pp 192-219

Zaner RM (1973b) Examples and possibles: a criticism of Husserl's theory of free-phantasy variation. Res Phenom 3(1):29-43

Ziemke T, Taguchi S (2019) The problem of meaning in AI and robotics: still with us after all these years. Philosophies 4(2):14. https://doi.org/10.3390/philosophies4020014

Publisher's Note Springer Nature remains neutral with regard to jurisdictional claims in published maps and institutional affiliations. 